\title{
Textiles y objetos arqueológicos: diferentes construcciones de sentido en torno a procesos de patrimonialización
}

\section{Textiles and archaeological objects: different ways of creating meaning in relation to heritage}

\author{
Soledad Biasatti ${ }^{1}$ y Jaquelina M. Salinas ${ }^{2}$
}

\section{Resumen}

Cuando desde las ciencias sociales indagamos acerca de la articulación entre Estado y la sociedad, la complejidad del tema parece desbordar cualquier aproximación. Sin embargo, intentaremos centrarnos en el modo en que determinadas normativas y políticas estatales adquieren y despliegan sentidos en la vida cotidiana de los sujetos. Aquí proponemos compartir un diálogo entre dos recorridos de investigación antropológica: por un lado, el trabajo con textiles y tejedoras, y por otro, el patrimonio arqueológico en el departamento Iglesia de la provincia de San Juan. Ambos recorridos interrelacionados permitirán realizar un contrapunto entre dos modos diferentes de construcción de sentido frente a lo patrimonial, así como también algunas reflexiones metodológicas y de género.

Palabras claves: políticas estatales, textiles, género, patrimonio.

\begin{abstract}
When, from the social sciences, we inquired about the articulation between State and society the complexity of the problem seems to exceed any approach. However, here we will focus on how certain regulations and state policies acquire and deploy meanings in the subjects' daily lives. We specifically propose a dialogue between two anthropological research: on the one hand fieldwork with textiles / weavers and, on the other hand, the archaeological heritage in the department Iglesia, Province of San Juan. Analyze both perspectives in relationship, will also allow two different ways of constructing meaning in relation to heritage and some reflections about methodology and gender.
\end{abstract}

Keywords: State politics, textiles, gender, heritage.

Recibido: 18 mayo 2016. Aceptado: 9 septiembre 2016

1 Universidad Nacional de Rosario. Entre Ríos 758, CP 2000, Rosario, Santa Fe. ARGENTINA. Email: solebiasatti@yahoo.com.ar

2 Centro de Estudios e Investigaciones en Arqueología y Memoria, Universidad Nacional de Rosario. Entre Ríos 758, CP 2000, Rosario, Santa Fe, ARGENTINA. Email: jaquelinasalinas@hormail.com 


\section{Introducción}

En este trabajo pretendemos articular un diálogo entre dos investigaciones que ambas autoras hemos desarrollado separadamente. ${ }^{3}$ La primera autora se ha enfocado en el estudio de las relaciones que se establecen entre los sujetos y los objetos (o sitios) del patrimonio arqueológico en el presente, poniendo énfasis en espacios institucionalizados como las colecciones y los museos, así como también en prácticas más específicas que despliegan algunos pobladores cuando recolectan objetos arqueológicos (los llevan o no a sus hogares, visitan sitios arqueológicos, entre otros); los significados que estos actos conllevan. Por su parte, la segunda autora se ha centrado en indagar sobre la construcción de las identidades en relación a la transmisión de conocimientos en las/os tejedoras/es en el departamento Iglesia, visualizando las representaciones que éstas construyen en torno a los procesos de traspaso de los saberes en la producción de textiles.

En este contexto en el que está involucrado el patrimonio cultural, median políticas culturales, políticas públicas, que responden a los objetivos de gobierno, mediante el diseño, gestión, administración, planificación y evaluación de programas puntuales que forman parte de las construcciones de sentido. Generalmente, las mismas son implementadas por instituciones estatales, aunque también pueden provenir de fundaciones, ONG, cooperación internacional y organizaciones de la sociedad civil, que pueden operar con o sin la autorización específica del Estado. El sector privado también incide en la conducción de políticas culturales, en concordancia, o no, con el Estado (Szurmuk e Irwin, 2009).

El punto de encuentro en este trabajo es la reflexión acerca del modo en que los sujetos se hallan inmersos en políticas estatales (en este caso, culturales) y cómo eso se traduce en distintos modos de significar las relaciones de: a) los pobladores masculinos y los

3 Este escrito ha recorrido un largo camino y ambas autoras hemos finalizado los trabajos de tesis (Biasatti 2016; Salinas 2018). A la distancia, encontramos líneas de análisis que podrían ser repensadas o profundizadas pero que decidimos mantener porque forman parte de un proceso de investigación ya transitado. objetos arqueológicos; b) las tejedoras y los textiles $y, c)$ entre ambos grupos de sujetos y nosotras como investigadoras.

Creemos que esta complementación será enriquecedora puesto que la tarea de escritura en solitario suele tornarse ensimismada. Es por ello que decidimos compartir el trabajo de campo realizado en comunidades de la localidad de Rodeo y otras vecinas del mismo departamento Iglesia (Figura 1).

\section{El espacio cotidiano como eje: los contextos de las entrevistas}

Nos interesa retomar nociones como "espacio doméstico", "casa" y "familia" debido a la aparente escisión entre la esfera familiar o grupo doméstico frente a las políticas estatales. Sin embargo, el espacio de lo público y lo privado está entrelazado a través de distintos mecanismos.

La idea de "familia" es una categoría de construcción colectiva. Si la familia aparece como "la más natural" de las categorías sociales y si, debido a ello, parece condenada a servir de modelo a todos los cuerpos sociales, es porque la categoría de "lo familiar" funciona, en los habitus, como esquema clasificatorio y principio de construcción del mundo social y de la familia como cuerpo social particular, que se adquiere en el seno mismo de una familia como ficción social realizada. La familia es, en efecto, fruto de una auténtica labor de institucionalización, a la vez ritual y técnica (Bourdieu, 1997). Por su parte, Margulis (2009) plantea una diferencia entre "familia" y "unidad doméstica", siendo que esta última designa a un determinado grupo que comparte una misma "unidad residencial" y que, generalmente, posee una economía común. El grupo de la unidad doméstica normalmente coincide con una familia que, junto con sus familiares consanguíneos, colaterales, exceden el ámbito espacial de la unidad doméstica. Esta idea asume una connotación espacial que nos resulta interesante recuperar para este trabajo debido a la delimitación de las actividades (tanto masculinas como femeninas) en distintos espacios domésticos. 


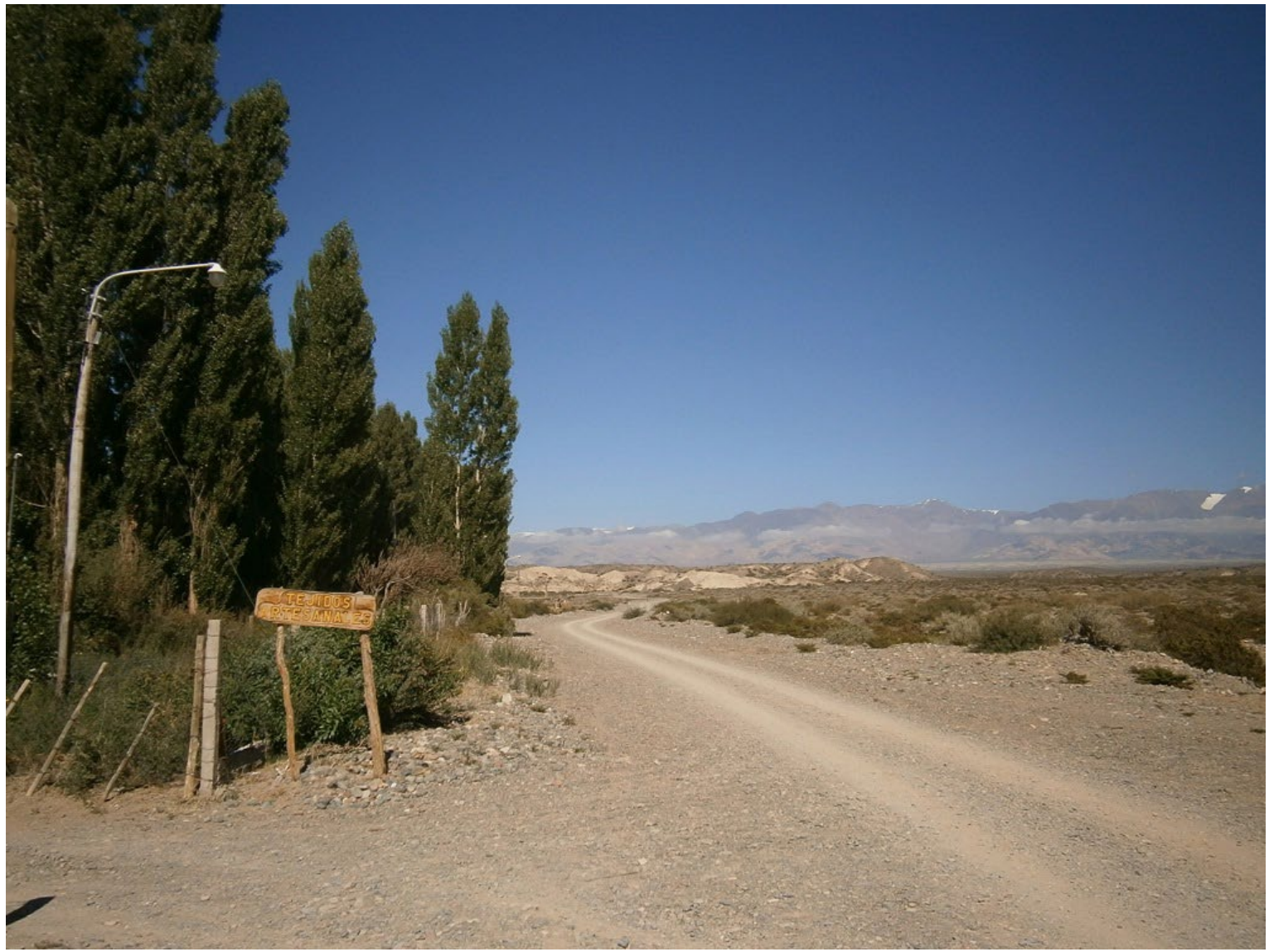

Figura 1. Letrero anunciando "Tejidos Artesanales" en Tudcum rodeado del paisaje de la cordillera iglesiana (enero de 2012). Fotografía tomada por las autoras.

El ámbito doméstico se delimita por el conjunto de actividades comunes o compartidas ligadas al mantenimiento cotidiano de un grupo social co-residente, que se conforman y cambian en su relación con las demás instituciones y esferas de la sociedad. Esto último implica considerar dos aspectos que atraviesan e identifican el ámbito doméstico: lo público y lo privado.

En este sentido, es interesante retomar a Bachelard (1965), quien indaga sobre la importancia que poseen los espacios cotidianos para construir imágenes poéticas de los mismos. A través de una investigación de las imágenes de la intimidad, Bachelard retoma la poética de "la casa". La casa es el primer mundo del ser humano, antes de ser "lanzado al mundo"; sin ella el hombre sería un ser disperso. El pasado, el presente y el porvenir dan a la casa diferentes dinamismos: "Para un estudio fenomenológi- co de los valores de intimidad del espacio interior, la casa es, sin duda alguna, un ser privilegiado, siempre y cuando se considere [...] a la vez en su unidad y su complejidad..." (1965, p. 35). Para el autor la casa es, entonces, el espacio de la "intimidad protegida".

Bourdieu (1972) en su análisis de "la casa kabilia" establece oposiciones entre la casa y el mundo exterior. Ésta se organiza según un conjunto de oposiciones homólogas: fuego-agua, cocido-crudo, arriba-abajo, luz-sombra, día-noche, masculino-femenino, fecundador-fecundable, cultura-naturaleza. Sin embargo, advierte que las mismas oposiciones existen entre la casa en su conjunto y el resto del universo. La casa -considerada en su relación con el mundo exterior, mundo propiamente masculino de la vida pública y del trabajo agrícola- es el universo de las mujeres, mundo de la intimidad y del secreto. 
Desde una metodología de investigación antropológica, nos orientamos a realizar entrevistas no estructuradas y observaciones (Guber, 2004), así como también el registro fotográfico y consulta de determinados documentos relacionados con las problemáticas de trabajo de cada una. También analizamos los lugares donde se desarrollaron dichas entrevistas en el marco de los espacios domésticos.

Es interesante notar que, si bien durante el trabajo de campo cada una iba pactando encuentros acordes con sus objetivos y haciendo su propio trabajo, decidimos no ceńirnos dentro de cada recorte sino, por el contrario, acompañarnos en las sendas que nos llevaba cada recorrido. Las entrevistas fueron realizadas con personas que eran reconocidas por "salir a buscar cosas o recorrer sitios arqueológicos" (todos son hombres) y a tejedoras (todas son mujeres; preguntamos a cada una de ellas y ninguna conocía a hombres que tejieran en la zona), así como también a integrantes del Parque Nacional San Guillermo y del área de Cultura de la Municipalidad de Iglesia.

En las familias, sus diferentes miembros participan en diversos contextos a través del cuáles construyen saberes, lo cual modifica implícita o explícitamente las posibilidades de aprendizaje de sus integrantes, al enriquecer cada una de las interacciones con las experiencias realizadas en los diversos ámbitos de acción (Dabas, 2003)

\section{Lo arqueológico}

En el área que forma parte de esta investigación se emplazan innumerables sitios arqueológicos, huellas materiales de la vida de las primeras poblaciones y de las que les sucedieron hasta la actualidad. No obstante, estas materialidades no han sido utilizadas únicamente por sus propios constructores, sino que en muchas ocasiones han sido reutilizadas, incluso con los mismos fines: refugios de caza, puestos en la cordillera, cementerios, caminos, entre otros (Escolar, 2007). Esto mismo ha sucedido con los objetos arqueológicos que, en muchos casos, pueden encontrarse en superficie y en distintos estados de conservación (p.e., conanas, morteros, petroglifos, entre otros). Los pobladores, en su totalidad han sido hombres, según nos mencionan en entrevistas- solían recolectar puntas de flechas en Viernes Santo, volvían a enterrar los restos humanos indígenas al encontrarlos mientras hacían trabajos agrícolas o de construcción, los ofrendaban como obsequio a parientes y amigos, los coleccionaban en sus hogares. Es una práctica marcadamente masculina debido a que "el campo" (el "afuera", la cordillera, las áreas de cultivo, zonas de pastoreo y arriería, entre otros) es el espacio donde los hombres desarrollan sus labores. Si bien es común que los hijos acompañen a sus padres en estas tareas, no siempre se traspasa de una generación a otra el interés por "lo arqueológico".

Podemos considerar entonces que, estas (y otras) prácticas en relación a "lo arqueológico", devenidas de la vida cotidiana en las inmediaciones de los sitios -y de otros motivos entre los que se entrelazan identidades, apegos, apropiaciones, expropiaciones-, se han sucedido tradicionalmente en la zona. Sin embargo, a partir de las legislaciones cada vez más estrictas sobre "patrimonio arqueológico", las mismas, se han visto empujadas a una reconfiguración.

Dichas legislaciones, han considerado que los objetos y sitios arqueológicos denominados "patrimonio" forman parte de un acervo y/o conjunto de bienes culturales de un pasado "de interés excepcional" y "digno de ser conservado" para "futuras generaciones" (Figura 2). El "patrimonio" es una noción relativamente reciente; ha sido legislado de manera acentuada a nivel internacional, después de la Segunda Guerra Mundial y es custodiado por el Estado (nacional, provincial y municipal), descansando sobre supuestos proteccionistas, conservacionistas, académicos y legalistas que, en nombre de entidades supranacionales, nacionales o provinciales, sostienen una potestad sobre lo arqueológico. En el caso que vamos a analizar, aplican algunas legislaciones que mencionaremos brevemente.

Desde 1972,4 la UNESCO (Organización de las Naciones Unidas para la Educación, la Ciencia y la Cultura), ha desarrollado una serie de convenciones y declaraciones en donde se acotan, especifican e

4 Convención sobre la protección del patrimonio mundial, cultural y natural. Firmada en París el 21 de noviembre de 1972. 


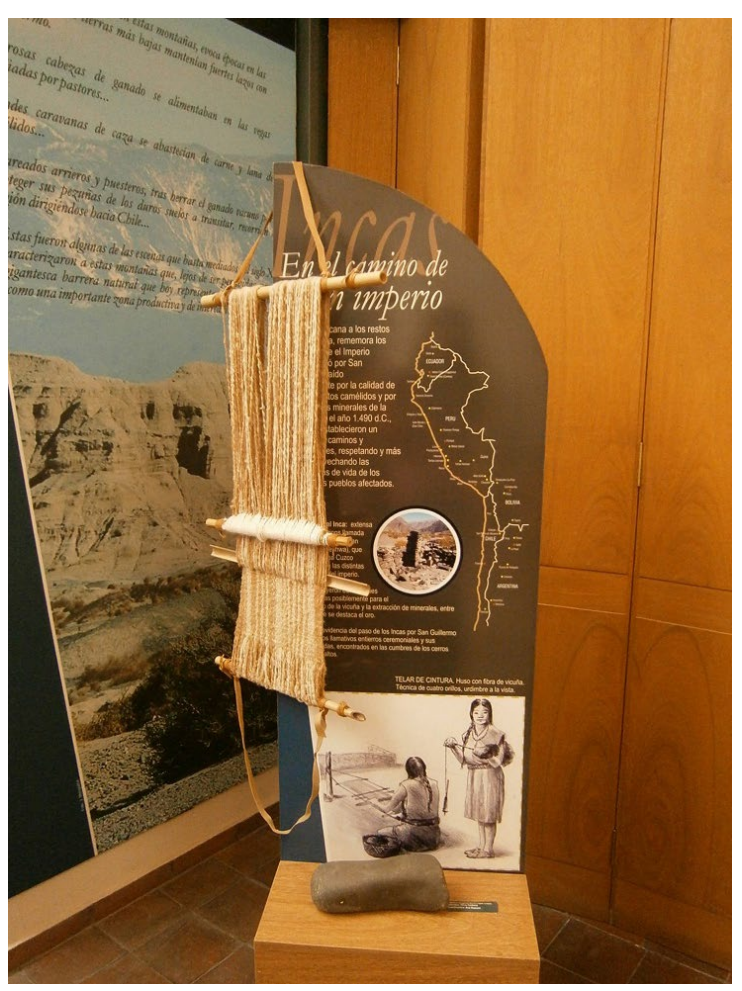

Figura 2. Montaje sobre técnicas textiles incaicas en Intendencia del Parque Nacional San Guillermo (enero de 2012). Fotografía tomada por las autoras.

inventarían elementos del "patrimonio" (cultural, natural, material, inmaterial, entre otros).

En Argentina, el objetivo de la Ley Nacional 25.743 (sancionada en 2004) es la preservación, protección y tutela del patrimonio arqueológico y paleontológico "como parte integrante del Patrimonio Cultural de la Nación y el aprovechamiento científico y cultural del mismo", 5 y tiene aplicación en todo el territorio nacional.

En el caso de la provincia de San Juan, se cuenta con la Ley Provincial No 6801 de Protección, Conservación, Restauración, Acrecentamiento y Difusión de todos aquellos bienes que conforman el Patrimonio Cultural y Natural de la Provincia de San Juan sancionada en $1997^{6}$ que descansa en algunos de estos mismos supuestos.

5 Puede consultarse en: http://www.inapl.gov.ar/renycoa/ leynacional.html

6 Puede consultarse en la página de la Cámara de Diputados de la Provincia de San Juan.
Estas normativas establecen que el "patrimonio arqueológico" debe ser conservado y protegido para futuras generaciones, y para ello debe ser inventariado y declarado ante el organismo competente. ${ }^{7}$ Es interesante notar que, paralelamente a la creación del "Registro Nacional de Yacimientos, Colecciones y Objetos Arqueológicos" se crea el Registro de Infractores y Reincidentes (bajo Resolución 1134/2003). ${ }^{8}$ Vemos entonces que las normas de protección y de sanción nacen a la par. Esta reconfiguración establece que los objetos deben ser notificados a dichos organismos y que los pobladores no pueden levantarlos, guardarlos, ni poseerlos en sus casas, ya que justamente estas normas propician un mecanismo legal y burocrático a seguir. El procedimiento indica que los objetos arqueológicos que se encontraran azarosamente deben ser informados a fin de que los profesionales arqueólogos a cargo de los operativos "de rescate" realicen las excavaciones y el traslado de los hallazgos a las instituciones adecuadas (museos, universidad) para ser analizados. En el caso del norte de San Juan, los objetos que entran en este curso legal son trasladados a la capital provincial.

Surgen varios puntos interesantes para el análisis cuando a través de ese acto de "normalización" se prescinde de algunos significados sociales mediante los cuales los objetos y sitios definidos como "patrimonio arqueológico" son investidos y disputados por otros grupos locales que interactúan o conviven con ellos (Biasatti y Aroca, 2007 Ms.; Biasatti y Jofré, 2008 Ms.; Jofré y González, 2008; Jofré et al., 2009). Es por estos motivos que las políticas patrimoniales llegan a las poblaciones a través de los lemas proteccionistas de "denunciar" y "no tocar” por sobre las diferentes prácticas que los sujetos realizan (o realizaban previamente) en relación a "lo arqueológico".

7 En nuestro país este Registro Nacional está a cargo del INAPL (Instituto Nacional de Antropología y Pensamiento Latinoamericano), aunque el mismo posee órganos provinciales de aplicación.

8 Puede consultarse en: http://www.inapl.gov.ar/renycoa/ leynacional.html 


\section{Los textiles}

Por su parte, la actividad de tejer en las localidades pertenecientes al norte de San Juan es específicamente femenina. Se comienza a muy temprana edad, constituyéndose en una práctica que se realiza todos los días dentro del ámbito doméstico.

Es la mujer quien transmite el conocimiento a sus hijas; en algunas ocasiones los hombres intervienen en la construcción de los elementos necesarios para desarrollar la actividad: fabricación del huso, de las agujas de crochet, del telar, de los peines. Aprender a tejer en telar implica una serie de pasos previos, de prácticas y de conocimientos. A los seis o siete ańos se comienza con el hilado, luego se practica con técnicas como el crochet y dos agujas. A la edad de 13 o 14 ańos se comienza con el telar. Lo anterior se desprende de los relatos de las tejedoras:

Aprendi de muy niña, comencé como se dice a jugar con la lana, habia un señor que tenía acá muchas ovejas, y pasaban por los alambrados $y$ dejaban la lana en los alambrados, y yo y una hermana mía ibamos a juntar la lana esa, y mi papá nos preparó un huso, comenzamos jugando a hilar a hilar hasta que lo aprendimos bien...y después mi padre nos hizo agujas de tejer al crochet, haciamos bufandas, y asi ibamos aprendiendo, después dos agujas y más grandes aprendimos a tejer con el telar. En el telar aprendi a los 14 o 15 años. Yo aprendi de mis antepasados, de mi abuelita y de mi madre. Fuimos aprendiendo a mejorar la calidad de artesanias, por ejemplo teñido, hacer dibujos, guardas, todo eso lo hemos aprendido después...cuando uno es más grande (entrevista con tejedora iglesiana, enero de 2012).

El tipo de telar que utilizan tiene algunas características específicas que hacen que una nińa no pueda manipularlo, se necesita fuerza y altura para los pedales y debido al peso de las prendas, el manejo de los lisos y montar la urdimbre (Figura 3).

El conocimiento transmitido se basa en la oralidad y en la práctica de un saber que se va vivenciando, mirando, aprehendiendo. Cuando las jóvenes son más grandes, y dadas las dimensiones del telar que se caracteriza por una estructura firme al suelo que

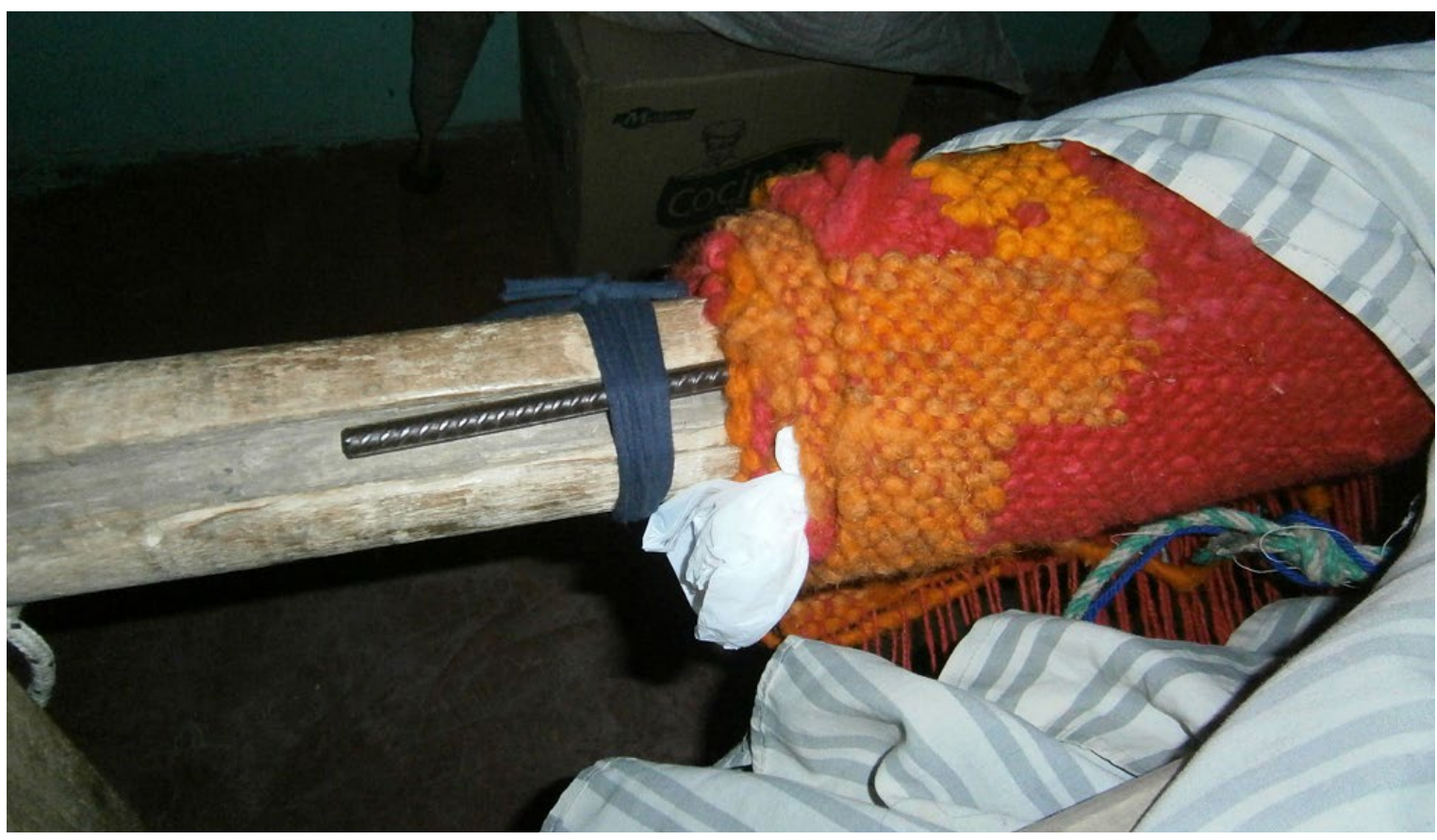

Figura 3. Palo envolvedor, elemento del telar denominado "criollo" (enero de 2012). Fotografía tomada por las autoras. 
ocupa un buen espacio, el tejer se transforma en una actividad solitaria. Los procesos colectivos en el telar se limitan a etapas previas (hilado, aprendizaje de nuevos diseños) o posteriores (producto elaborado). Algunas veces, junto al telar encontramos sillones y mesas en donde otras mujeres que forman parte del grupo doméstico, bordan y tejen a dos agujas.

Las experiencias formativas como tejedoras se constituyen durante la socialización primaria, que comporta secuencias de aprendizaje socialmente definidas y que presentan una gran variabilidad histórico-social en la definición de dichas etapas de aprendizaje. El carácter de la socialización primaria también resulta afectado por las exigencias del acopio de conocimiento que debe transmitirse, y por la carga emocional del niño con sus otros significantes, que se instituyen como mediadores de la realidad, en los cuales el nińo o la nińa internalizan el mundo de sus padres como el mundo y no como perteneciente a un contexto social específico (Berger y Luckmann, 1993).

Las tejedoras entrevistadas continuaron con experiencias formativas aunque, en algunos casos, éstas fueron interrumpidas por problemas económicos que las obligaron a ir a trabajar como empleadas domésticas a otros lugares. La continuidad de su formación y el perfeccionamiento en actividades textiles se desarrollaron durante la adultez.

En este sentido, podemos plantear la presencia -en las tejedoras- de nuevas formas de reconfiguración de sus prácticas, del espacio doméstico y de su identidad en relación a las demandas emergentes del contexto económico, político y social.

En el año 2007, se implementó un proyecto desde la Secretaría de Desarrollo Sustentable financiado por el Banco Mundial, bajo la asistencia técnica contratada por la Administración de Parques Nacionales ${ }^{9}$ en cuatro comunidades cercanas al Parque Nacional, ubicadas al norte del departamento. Éstas son Colangüil, Angualasto, Malimán y Tudcum.

9 Entrevista en Intendencia del Parque Nacional San Guillermo, provincia de San Juan.
Dicho proyecto se denominó "Manos de los Andes", nombre que actualmente se utiliza para la venta de los tejidos. Entre sus objetivos se planteaba la necesidad de garantizar el desarrollo sustentable de las comunidades creadoras de artesanías; resguardar la autonomía e identidad cultural de las comunidades; la defensa y promoción de la diversidad por medio del incentivo de la producción artesanal; revalorizar las artesanías tradicionales y étnicas (que por sus características funcionales o utilitarias, empíricas, anónimas, patrimonio comunitario y transmitidas de generación en generación, poseen un valor estético y cultural que las convierte en un recurso que despierta creciente interés) y, finalmente, preservar, promocionar y multiplicar la actividad artesanal como una práctica socioeconómica y cultural que posibilita el desarrollo de las comunidades locales.

La puesta en marcha de estos objetivos, concretamente, consistió en subsidios que se otorgaban a proyectos presentados por una familia y que podían ser utilizados para herramientas, equipos e insumos necesarios para optimizar la calidad de la producción, capacitación en el uso de herramientas nuevas, actividades grupales, dinámicas y participativas de perfeccionamiento y adaptación en el mercado, para la producción de artesanías (diseńo, calidad, control de costos) y difusión de producciones artesanales al mercado local y regional.

Los integrantes del Parque Nacional San Guillermo plantearon que:

[...] se hizo el relevamiento de cuáles serian los proyectos más aptos para aplicar. Fue justamente ayudar y colaborar a las tejedoras de acá del departamento, básicamente las del norte. Y lamentablemente la mayoría están en Tudcum, y no así como en las comunidades más norteñas como Colangüil, Angualasto, Malimán no hay tejedoras, inclusive las otras tejedoras de importancia del departamento están en Villa Iglesia que eran en su momento habitantes de Cerro Negro acá en Rodeo, son las tejedoras muy importantes, por su calidad de tejido, por su obra que atraviesa. Estos proyectos básicamente se orientaron a facilitar, este eh... herramientas (enero de 2012). 
Otro proyecto promovido desde la Dirección de Cultura de Rodeo, fue impulsado con el fin de recuperar técnicas o saberes tradicionales en relación al trabajo artesanal, aunque podemos visualizar que, en cierta medida, esto significaba introducir sus productos en un circuito comercial y/o turístico.

En palabras de los encargados culturales, la idea que subyace es:

\section{[...] recuperar que no se pierdan las enseñanzas,} técnicas del telar, como hilar. Todo el proceso que tiene hasta llegar a la prenda. Nosotros tenemos el año pasado, el 25 de noviembre, que se inauguró el nodo turístico que concentra una sala de exposición de artesanias y productos de la zona y también darle la promoción al artesano. El artesano hace sus cosas y las tiene en su casa en una caja, no, nosotros queremos que hagan sus productos y exhibirlos para la venta. En Pismanta, ubican el hotel de Pismanta, bueno, al frente... un edificio grande... ahi hay productos regionales, productos locales, que los artesanos preguntan para qué hacemos si amontonamos en mi casa y no lo vamos a vender. Esta es la idea del nodo de vender, de promocionar el producto del artesano... (enero de 2012).

Ambos proyectos que provienen de instituciones públicas de la región comparten objetivos que si bien apuntan a potenciar la actividad textil, sus formas de implementación son pautadas desde dichas entidades, dejando a las tejedoras en una relación de desigualdad en relación a la toma de decisiones.

Las tejedoras que participaron de proyectos gubernamentales, de empresas transnacionales radicadas en la zona o de organizaciones no gubernamentales transformaron el espacio donde realizan sus prácticas textiles. Esto se evidencia en: la construcción de un espacio para la confección y venta de los tejidos fuera del ámbito doméstico; la incorporación de mobiliario (vitrinas, estantes); el equipamiento de nuevos telares, la introducción de estrategias de venta y marketing (carpeta con fotos, folletería, exhibición de muestras). Un cambio fundamental es que el telar se exhibe como dispositivo de venta, es decir que, ante el regateo del precio por parte del comprador, la tejedora lo muestra para fundamentar su laboriosidad y el precio de la prenda. Así, el telar juega un rol que varía entre lo privado y lo público, dejando de estar circunscrito al ámbito privado para pasar a cumplir un rol diferente y ser parte de un posicionamiento dentro de un campo de fuerzas (Bourdieu, 1997).

A su vez, expresan nuevas formas de simbolización, que construyen las maneras de ver, percibir y actuar en función de la implementación de una nueva lógica relacionada a las exigencias de un mercado y de proyectos culturales. Por ejemplo, para cubrir la demanda turística, algunas tejedoras solicitan, a su vez, tejidos de otras tejedoras: "Ella viene, que le teja una cosa o la otra, a veces caminos y otras colchas" (entrevista con tejedora iglesiana, enero 2012).

Pudimos visualizar dos variantes en cuanto al funcionamiento de talleres, ubicados en patios y/o externos al ámbito residencial: por una parte, aquellos cuyas características edilicias eran "precarias" y por lo tanto la actividad artesanal se encuentra sujeta al clima (ya que no se puede tejer con mucho frío o con mucho calor) y, por otra, construcciones "estables" realizadas a través de la participación de la tejedora en proyectos (en donde el taller se fue conformando como un ámbito de trabajo separado de la cotidianeidad residencial).

Estas formas de planificación, organización y distribución del espacio (del taller, de ventas y familiar) y del tiempo (de trabajo, de venta, familiar) constituyen dinámicas que visualizan las formas en que inciden las políticas culturales (Figura 4).

Finalmente, mencionaremos que algunos relatos provenientes de diferentes ámbitos afirman que "las mujeres jóvenes ya no quieren tejer más y que prefieren vivir de los planes de ayuda social". Sin embargo, a través de las entrevistas a los distintos miembros de la unidad doméstica, notamos que el discurso que prevalece es el que señala que la textilería no es una actividad productiva redituable a causa del tiempo que conlleva, los altos costos de los materiales y la venta, motivo por el cual se dedican a otras actividades en relación de dependencia en localidades vecinas o en la ciudad de San Juan (Salinas, 2012 Ms.). 


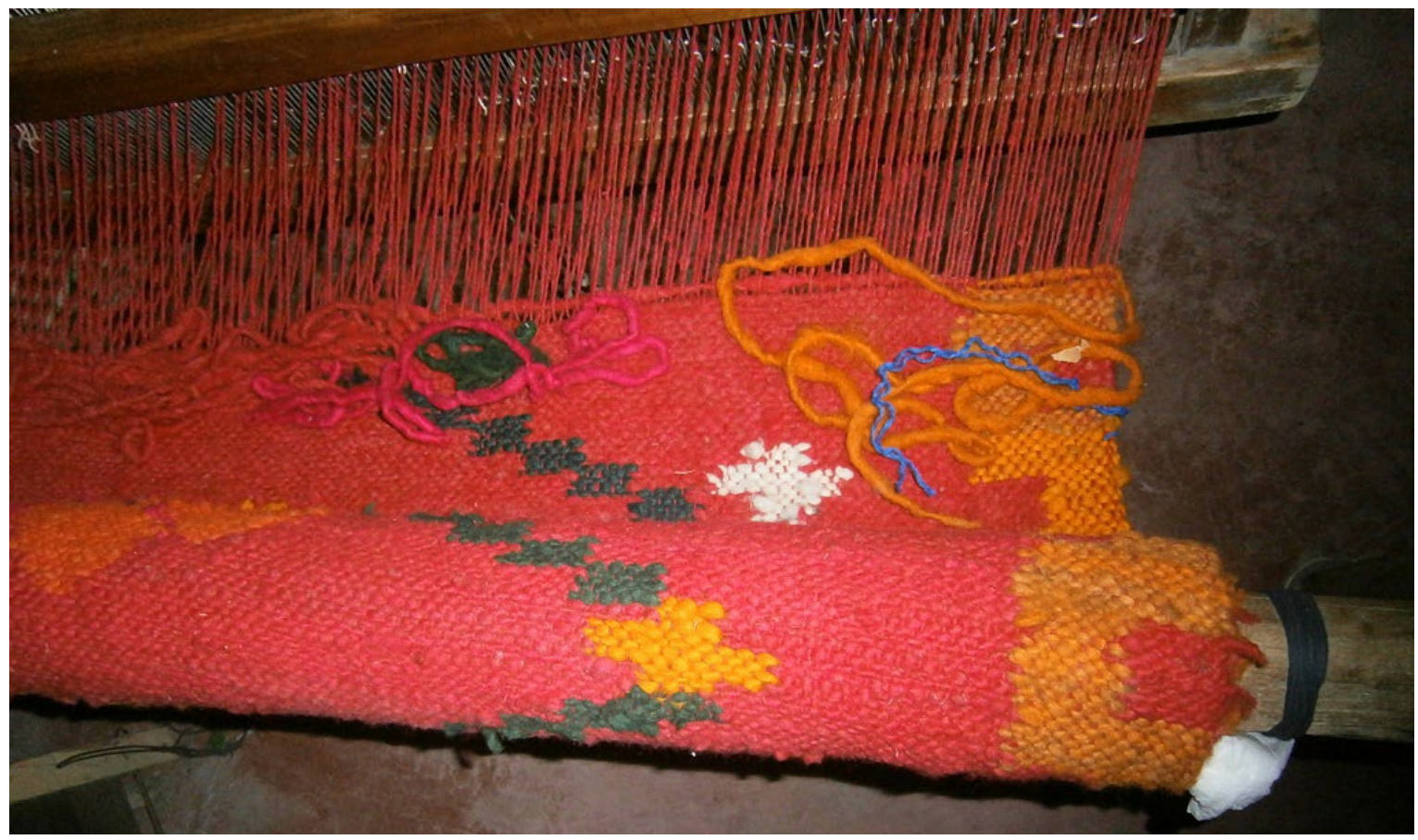

Figura 4. Manta realizada por una de las tejedoras de la localidad de Tudcum (enero de 2012).

Fotografía tomada por las autoras.

\section{Discusión de los resultados}

Desde un principio nos llamaba la atención que a una de nosotras (segunda autora) le resultara muy sencillo pactar sus entrevistas. De allí la derivaban de una tejedora a otra, le daban el nombre, apellido, dirección, teléfono y ella las llamaba y llegaba con intención de entrevistarlas y grabarlas, sin ningún inconveniente. No le preguntaban demasiado de qué se trataba el trabajo que estaba realizando, ni les generaba dudas su profesión, tampoco que viniera "de afuera" a interesarse por sus tejidos. Enseguida mostraban sus tejidos, que la mayoría de las veces estaban a la vista o en uso, traían sus herramientas de trabajo, sus telares, los libros y fotocopias de donde obtenían diseños, explicaban sobre las tinturas naturales, traían semillas para mostrar. No ponían objeciones para fotografiar y grabar.

Esta situación se contraponía con los encuentros buscados por otra de nosotras (primera autora), que eran más difíciles de pactar, cuestionadas las intenciones, el origen foráneo, la profesión, la universidad a la que pertenecía, entre otros. Los "objetos" eran traídos al final del encuentro, en su mayoría no estaban a la vista sino envueltos y en cajas, se solicitaba regresar en otra ocasión para mostrarlos, hacían apagar el grabador por momentos, dejaban claro que eran elementos que poseían desde hacía mucho tiempo (anterior a la legislación) o mencionaban "anécdotas" que daban cuenta de sus conocimientos sobre lugares y objetos arqueológicos, aunque aclaraban que habían dejado "todo como estaba".

Por ello, nos detuvimos en el lugar de cada una en relación a los temas de investigación y nos surgieron una serie de reflexiones.

En primer término, una cuestión de "género" atravesó los recorridos tanto de los sujetos investigados como de los sujetos investigadores. Este punto se podía apreciar, además, en el "espacio". Una de nosotras (segunda autora) es una mujer preguntando y hablando sobre temas femeninos en espacios con predominio femenino, es decir, dentro de las casas, que es donde se desarrolla la actividad sobre la cual se consultaba (aunque es de notar que la mayoría de los objetos que tejen son para actividades 
masculinas relacionadas con caballos: jergones, monturas, peleros, alforjas, ponchos y mantas).

Por el contrario, la otra (primera autora) es una mujer indagando sobre temas masculinos en espacios femeninos (las casas de cada uno de los entrevistados). Es preciso señalar aquí que los hombres en general no eran alentados por sus familias a hacer esa actividad. El hecho de "salir a buscar cosas de indios" era cuestionado por sus mujeres, lo que fue mencionado en varias entrevistas. Las mujeres temen que los "restos arqueológicos" traídos dentro de las casas puedan "asustar" durante la noche (nos narraban una serie de sonidos que escuchaban asociados a los mismos), y por eso obligaban a los hombres a conservar aquellos objetos en espacios no-hogareños. También se argumentaba que "ocupan mucho lugar" y que "son cosas que se acumulan ahí sin mucho sentido". Esta idea de las casas como espacios con predominio femenino se acentuó cuando en las entrevistas de la segunda autora nos hacían pasar a la cocina o comedor, y luego a la habitación donde se teje (o a algún espacio que, en general, suele ser específico para esto), mientras que en el caso de la primera autora nos atendían usualmente en el patio o en el lugar de trabajo.

Los estudios de género constituyen un área de conocimiento que puede brindarnos algunas herramientas para abordar las situaciones que hemos descrito. Por una parte, permiten hacer visibles los mecanismos sociales y de poder mediante los cuales se construyen las representaciones y prácticas de "lo femenino" y de "lo masculino", que ordenan a los sujetos en varones y mujeres; por otra, las resistencias subjetivas que hacen fracasar -con mayor o menor radicalidad- estos mandatos sociales (Morroni, 2007). Estos estudios, junto a una serie de movimientos sociales que se han venido intensificando en los últimos años, permitieron revisar críticamente las "naturalizaciones" con las que el patriarcado, a través de sus instituciones y sus discursos sociales reproducía y reproduce la condición devaluada de las mujeres respecto de los varones. Sin embargo, diferentes instituciones continúan reproduciendo y legitimando en el imaginario social unos modos de existencia en detrimento de otros.
Lamas (1996) aborda el género como construcción cultural que se lleva a cabo en función de los sexos biológicos, al distinguir entre "la asignación de género", "la identidad de género" y el "rol de género".

Como plantea Castro Ricalde (2009), las marcas del género, están presentes en cada momento de la existencia de los seres humanos, inmersas en las prácticas sociales y se ven influidas por el momento histórico y el contexto. Es decir, las conductas esperadas de los individuos, según sean identificados como hombres o mujeres, y lo que significa pertenecer a uno u otro sexo, varían no solo de país a país, que además, se han modificado a lo largo de su historia, sino que también, dependen del posicionamiento de los sujetos en los espacios de la vida cotidiana y el tipo de relaciones establecido entre quienes actúan como sus interlocutores. De aquí el interés por estudiar las múltiples intersecciones del género con otras variables como el grupo étnico, la clase social y la edad.

A partir de lo anterior, nos preguntamos acerca de las posibles relaciones esperables entre género y rol de género, es decir, cuáles son los temas socialmente legitimados que pueden ser abordados por la mujerarqueóloga en el trabajo de campo. Una práctica que se entrelaza con los espacios, discursos y actores sociales constituyendo tramas y/o redes de significación que ponen en juego los estereotipos de género, es decir, representaciones simplificadas, incompletas y generalizadas que se realizan teniendo como base el sexo biológico. Estos estereotipos funcionan a partir de asociar una pauta cultural (un rol esperado, una norma, un mandato, etc.) con un hecho biológico. A su vez, la perspectiva de género constituye una forma de mirar la realidad y las relaciones entre los hombres y las mujeres mediadas por las dinámicas de poder. Problematizar las concepciones rígidas sobre lo considerado exclusivamente masculino o exclusivamente femenino, identificando prejuicios y estereotipos de género, fue constitutivo de las reflexiones durante el trabajo de campo.

Otro de los ejes de análisis se refiere propiamente al tipo de objeto sobre el cual indagamos en las entrevistas, éstos son promovidos por políticas culturales diferenciadas que se desplegaron en el modo de mostrarnos/no mostrarnos: los textiles se elaboran 
en el ámbito íntimo, pero son destinados a otros (para mostrar, vender, usar, llevar a ferias, participar en concursos de artesanos, etc.), y en cambio "lo arqueológico" se extrae del exterior para introducirlo en un ámbito íntimo y/o privado (muchas veces los objetos están escondidos de la mirada ajena dentro de cajas o envueltos), y también por tratarse de "objetos ilegales" que no deben mantenerse en los hogares sino en museos o universidades, como ellos han aprendido; que no son para ser mostrados, o bien solamente para ser mostrados a unos pocos "entendidos" que los sabrán apreciar o "valorar".

\section{Consideraciones finales}

Waisbord (2009) señala que las diversas oportunidades para la participación cultural están contextualizadas por las desigualdades de poder, de recursos y acceso. Es decir, que el concepto remite a dos ideas ambiguas y discutidas. Por un lado, como "consumo de bienes", en la que ésta no es democratizante, pero sí fundamental para el funcionamiento de un sistema desigual de producción cultural. La otra idea a la que hace referencia es a la "participación como producción de sentido": el hecho de vivir socialmente determina que los seres humanos no pueden "no participar" culturalmente en tanto están inmersos en "redes de sentidos". Para este autor, el desafío consiste en identificar el tipo de oportunidades que una sociedad genera para la producción de significados.

Las políticas desarrollistas de intervención orientadas por modelos de modernización juegan un rol preponderante en las lógicas de expropiación que a diario asisten a los sujetos en las nuevas subjetividades globales capitalistas. En este contexto, las prácticas y saberes tradicionales pasan a ocupar el lugar de "recursos para la oferta turística" o "patrimonio de todos" (lo "propio" para "otros"). De esta manera, los tejidos/objetos arqueológicos como parte constitutiva del patrimonio cultural (y más allá de los juegos de oposiciones y resistencias analizados) quedan inscritos en esta dinámica.

\section{Agradecimientos}

A las tejedoras y a los pobladores del departamento de Iglesia que nos compartieron sus saberes. El presente trabajo fue realizado en el marco de los trabajos de tesis doctoral de Soledad Biasatti, subsidiados por CONICET, y de maestría de Jaquelina Salinas, subsidiados por el Fondo Nacional de las Artes. Ambos son continuidad de investigaciones radicadas en la Universidad Nacional de Catamarca, que estuvieron a cargo de la Dra. Carina Jofré con intervenciones de Cayana Colectivo de Arqueología. Agradecemos a la Dra. Sara M. L. López Campeny y a la Dra. Carolina Agüero Piwonka la invitación para participar en esta publicación temática, a fin de compartir las presentaciones del Simposio realizado en el $55^{\circ}$ Congreso Internacional de Americanistas, en San Salvador. Este escrito ha sido enriquecido por los comentarios y sugerencias de los evaluadores, a ellos nuestro agradecimiento.

\section{Referencias citadas}

Bachelard, G. (1965). La poética del espacio. Ciudad de México: FCE.

Berger, P. y Luckmann, T. (1993). La construcción social de la realidad. Buenos Aires: Amorrortu.

Biasatti, S. (2016). Arqueología e Identidades: Procesos de integración sociocultural del patrimonio arqueológico (Provincia de San Juan). Tesis de posgrado para optar al grado de Doctora en Ciencias Antropológicas, Universidad Nacional de Córdoba (dirigida por el Dr. Diego Escolar).

Biasatti, S. y Aroca, P. (2007) Ms. Museos, colecciones y coleccionistas: reflexiones sobre el patrimonio arqueológico en la Provincia de San Juan. Trabajo presentado en XVI Congreso Nacional de Arqueología Argentina. San Salvador de Jujuy.

Biasatti, S. y Jofré, C. (2008) Ms. El pasado indígena relatado en museos de la Provincia de San Juan: libros de visitas y entrevistas. En CD de IV Jornadas de Trabajo sobre Historia Reciente. Universidad Nacional de Rosario, Rosario. 
Bourdieu, P. (1972). La casa o el mundo invertido (segundo estudio de etnología kabilia). Esbozo de una teoría de la práctica precedido de tres estudios de etnología kabilia.

http://www.humanas.unal.edu.co/colantropos/documentos/BourdieuLacasa2.pdf

Bourdieu, P. (1997). Razones prácticas. Sobre la teoría de la acción. Barcelona: Anagrama.

Castro Ricalde, M. (2009). Género. En Szurmuk, M. e Irwin, M. R. (Eds.). Diccionario de estudios culturales latinoamericanos (pp.112-119). Ciudad de México: Siglo XXI.

Dabas, E. 2003. Redes sociales, familias y escuela. Buenos Aires: Paidós.

Escolar, D. (2007). Los dones étnicos de la nación. Identidades huarpe y modos de producción de soberania en Argentina. Buenos Aires: Prometeo Libros.

Guber, R. (2004). La etnografia, campo y reflexividad. Buenos Aires: Norma.

Jofré, C. y González, G. (2008). En la radio han dicho que no se puede tocar nada... Reflexiones sobre el patrimonio arqueológico en la Provincia de San Juan (República Argentina). Revista Chilena de Antropologia, 19, 117-141.

Jofré, C., Biasatti, S., Compañy, G., González, G., Galimberti, M. S., Najle, N. y Aroca, P. (2009). La cayana: entre lo arqueológico y lo cotidiano. Tensiones y resistencias en las versiones locales del "patrimonio arqueológico" en el norte de San Juan. Revista Relaciones de la Sociedad de Antropologia Argentina, XXXIII, 181-207.
Lamas, M. (1996). Hablemos de sexualidad, lecturas. Ciudad de México: CONAPO.

Margulis, M. (2009). Sociología de la cultura: conceptos y problemas. Buenos Aires: Biblos.

Morroni, L. (2007). Generando géneros. Cuestionamientos de las identidades genéricas desde la teoría feminista. Revista El Monitor de la Educación (5a época), 11, 38-40.

Salinas, J. (2012) Ms. Informe final Proyecto Hilando historias: la construcción de las identidades en relación a la transmisión de conocimientos en las/os tejedoras/es del Departamento Iglesia (Provincia de San Juan). Fondo Nacional de las Artes.

Salinas, J. (2018). Mujeres tejedoras del norte sanjuanino: entre vellones de auquénidos y la urdimbre sarmientina. Tesis de posgrado para optar al grado de Magíster en Estudios Culturales, Universidad Nacional de Rosario (dirigida por la Lic. Claudia Gotta).

Szurmuk, M. e Irwin, M. R. (Eds.). (2009). Diccionario de estudios culturales latinoamericanos. Ciudad de México: Siglo XXI.

Waisbord, S. (2009). Participación cultural. En Szurmuk, M. e Irwin, M. R. (Eds.). Diccionario de estudios culturales latinoamericanos (pp. 203-207). Ciudad de México: Siglo XXI. 